\title{
MORPHOLOGICAL FINDINGS IN INTRAUTERINE GROWTH RESTRICTION (IUGR) PLACENTAS VERSUS NORMAL PLACENTAS IN PREGNANT WOMEN OF DISTRICT RAWALPINDI, PAKISTAN
}

\author{
Nazma Kiran', Nadia Aslam', Tahira Tabassum², Saadia Kanwal ${ }^{3}$, Tanveer Zia ${ }^{1}$ \\ Departments of Pathology, ${ }^{1}$ Rai Medical College, Sargodha, ${ }^{2}$ Sargodha Medical College, Sargodha, ${ }^{3}$ Zainab \\ Memorial Hospital, Rawalpindi, Pakistan
}

\begin{abstract}
Background: Intrauterine growth restriction (IUGR) is a principal cause of fetal and neonatal morbidity and mortality. The placenta, as a vector for maternal-fetal nutrient and oxygen exchange has major influence on birthweight. The objectives of this study were to compare the placental weight (grams), number of syncytial knots and number of blood vessels in villi of IUGR placentas versus normal placentas.

Materials \& Methods: This cross-sectional study was carried out at Rai Medical College, Sargodha, Pakistan in collaboration with Zainab Memorial Hospital, Rawalpindi, Pakistan from December 2016 to November 2018. Study group included 45 IUGR placentas and control group included 25 normal placentas. Placental weight in grams, number of syncytial knots and number of blood vessels in villi of placentas were three research variables. These were described by mean, minimum, maximum, range and standard deviation for each group separately and were compared between the two groups through independent-samples t-test.

Results: Descriptively the mean placental weight in grams in IUGR group (423.35 $\pm 64.13 \mathrm{~g})$ was lower than control group placentas $(535.92 \pm 44.57 \mathrm{~g})$. The number of syncytial knots in IUGR group placentas $(22.04 \pm 5.21)$ was more than control group placentas $(13.84 \pm 4.41)$. The number of blood vessels in IUGR placentas was lower than control group placentas. All three null hypotheses for research variables between the two groups were rejected $(p=<.00001)$.

Conclusion: In this study, significant differences were found between the IUGR and normal placentas. All the major histologic findings pointed towards reduced blood flow to placentas resulting in restriction of blood flow to fetus.

KEY WORDS: Placenta; Intrauterine growth restriction; Birth weight; Placental villi; Fetal growth; Placental insufficiency.

This article may be cited as: Kiran N, Aslam N, Tabassum T, Kanwal S, Zia T. Morphological findings in intrauterine growth restriction (IUGR) placentas versus normal placentas in pregnant women of district Rawalpindi, Pakistan. Gomal J Med Sci 2019 Jul-Sep; 17 (3):65-9. https://doi.org/10.46903/gjms/17.03.2021
\end{abstract}

\section{INTRODUCTION}

\subsection{Background:}

The placenta, as a vector for maternal-fetal nutrient and oxygen exchange, is a major influence on birth weight. 'The kinetics of fetal and placental growth is

\section{Corresponding Author:}

Dr. Nazma Kiran

Associate Professor

Department of Pathology

Rai Medical College, Sargodha, Pakistan

E-mail: nazmakiran@hotmail.com

Date Submitted: 20-01-2019

Date Revised: $\quad 07-05-2019$

Date Accepted: $\quad 02-06-2019$ closely related, and it predicts postnatal health of the child. ${ }^{2,3}$ Growth of the fetus is dependent on oxygen and nutrient availability, which in turn is related to the uteroplacental blood supply, maternal diet and maturation of placental villi. At birth, the fetal and placental weight gives a reflection of the proficiency of the placenta to support fetal growth, and estimates the potential risks for the diseases in adult life..$^{3,4}$

Intrauterine growth restriction (IUGR) is a principal cause of fetal and neonatal morbidity and mortality. It is defined as a rate of fetal growth that is less than normal in light of the growth potential of that specific infant. IUGR infants may have many acute neonatal conditions including perinatal asphyxia, hypoglycemia, hypothermia, and polycythemia. The long-term complications of these infants include growth retar- 
dation, neurological disorders, and developmental diseases. ${ }^{5}$

IUGR can be the result of maternal, fetal or placental disorders. Maternal causes include hypertension (especially preeclampsia or eclampsia), diabetes mellitus, cardiopulmonary disease, anemia, malnutrition, connective tissue disorders, smoking and drug abuse. Fetal causes comprises of chromosomal abnormalities, ventral wall defect, or genitourinary defects. Placental causes are placental insufficiency, placental infarction and placental mosaicism. ${ }^{6}$ Recent literature suggests that placental causes of IUGR are more common than the maternal and fetal causes. ${ }^{7}$

Placental-related fetal growth restriction arises mainly due to deficient remodeling of the spiral arteries supplying the placenta during early pregnancy. ${ }^{8}$ The known placental pathology of an IUGR infant includes decrease in placental weight, infarction, increased syncytial knots, intervillous fibrin deposition, chronic villitis, avascular villi and stromal fibrosis. ${ }^{7,9}$

\subsection{Research Objectives:}

The objectives of this study were to compare the placental weight (grams), number of syncytial knots and number of blood vessels in villi of IUGR placentas versus normal placentas.

1.3 Significance: Our study will generate information about significance of the abnormalities related to placental weight, syncytial knots and blood vessels that lead to the development of IUGR. Such information can be used by other researchers on this topic and it can also be a useful adjunct in planning and management of future pregnancies.

\subsection{Research (Null) Hypotheses:}

$H_{0} 1$ : There is statistically no significant difference in the weight of IUGR placentas and normal placentas in pregnant women of district Rawalpindi, Pakistan.

$\mathbf{H}_{0}$ 2: There is statistically no significant difference in the number of syncytial knots in IUGR placentas and normal placentas in pregnant women of district Rawalpindi, Pakistan.

$\mathbf{H}_{0}$ 3: There is statistically no significant difference in the number of blood vessels in villi of IUGR placentas and normal placentas in pregnant women of district Rawalpindi, Pakistan.

\section{MATERIAL AND METHODS}

2.1 Design, Duration \& Setting: This cross-sectional study was carried out at the Department of Pathology, Rai Medical College, Sargodha, Pakistan from December 2016 to November 2018. The specimens were collected from Zainab Memorial Hospital, Rawalpindi, Pakistan.

\subsection{Population, Sample size, Technique \& Selec-} tion:

Zainab Memorial Hospital, Rawalpindi, Pakistan is one of many private hospitals offering obstetrical services to the population of district Rawalpindi. We would assume some 100 cases of deliveries with IUGR placentas and some 5000 cases of otherwise normal deliveries in the years 2017-2018 in the catchment area of this hospital. These would be our two populations from which we will draw respective and representative samples and on to which we will infer our results.

We assumed that true weight of IUGR placentas (Group 1- IUGR/ Study Group) is normally distributed with mean 425 grams and SD 43 grams. Similarly true weight of normal placentas (Group 2- Normal/ Control group) was assumed to be normally distributed with mean 460 grams and SD 53 grams. Here we desired the ratio of sample size (sample 2/ sample 1) as 0.55 , the minimal sample size to detect a difference with a power of $80 \%$ at $95 \%$ confidence level came to be 45 for Group 1 and 25 for Group 2, total 70, using 'Open Epi: sample size for comparing two means' program. ${ }^{10-11}$

Sampling technique was consecutive non-probability.

Inclusion criteria for IUGR group was all pregnant women with gestational age of 37 to 42 weeks, diagnosed with fetal IUGR and for control group was normal full term pregnancy (37-42 weeks). Exclusion criteria for both the groups were twin pregnancy, gestational hypertension, diabetes mellitus, smoking and congenital anomaly.

2.3 Conduct of Procedure: All these deliveries were conducted by the Obstetrician SK in Zainab Memorial Hospital, Rawalpindi, Pakistan. Immediately after expulsion, placentas were washed up in tap water to remove blood clots and preserved in $10 \%$ formalin solution. Thereafter these were transferred to Pathology Laboratory of Rai Medical College, Sargodha. Placenta of each patient was given a laboratory number. Weight of the placenta in grams was taken without umbilical cord. The placentas were equally divided into $1 \mathrm{~cm}$ sections and three representative sections were taken from each placenta. Additional sections were taken from pathological area. The tissues were processed and stained by $\mathrm{H} \& \mathrm{E}$ stain. The slides were then examined under light microscope. Number of syncytial knots was counted in 5 high power fields per slide using 40X objective. Numbers of villous blood vessels were calculated in 10 villi in 3 random fields per each slide under $10 \mathrm{X}$ objective. ${ }^{9}$

2.4 Data Collection \& Data Analysis Plan: Placental weight in grams, number of syncytial knots and number of blood vessels in villi of placentas were three research variables. The data type for these three variables was ratio (numeric). All these were described by mean, minimum, maximum, range and standard deviation, for each group separately for the sample. Estimated parameters for populations were given as confidence interval $(\mathrm{Cl})$ of mean. 
Each research variable was compared between the two groups through independent-samples t-test. Sample size, mean, SD for each group, mean difference, confidence interval $(\mathrm{Cl})$ of mean difference, degree of freedom, $t$ value and significance ( $p$-value) were given for each test separately. Data was analyzed by an online statistical calculator. ${ }^{12}$

\section{RESULTS}

3.1 Descriptive Statistics and Estimation of Parameter: Group 1 included 45 IUGR placentas and Group 2 included 25 normal placentas. Here statistics for the samples and relevant estimated parameters for the populations at risk are given as $\mathrm{Cl}$ at $95 \% \mathrm{CL}$. Descriptively the mean weight of placentas in IUGR group in sample and population is lower than the control group placentas. The number of syncytial knots in placentas in IUGR group in sample and population is more than the control group placentas. The number of blood vessels in placentas in IUGR group in sample and population is lower than the control group placentas. (Table 1) (Figure 1)

The number of vessels per terminal villus ranged from 2 to 6 in control group. The IUGR placentas showed hypovascular or avascular villi. (Figure 2)

\subsection{Hypotheses Testing:}

$\mathbf{H}_{0}$ 1: Here the mean weight of IUGR placentas was compared to mean weight of control group placentas through independent-samples t-test at alpha .05. As $\mathrm{p}$-value was less than 0.05 , hence $\mathrm{H}_{0} 1$ was proved to be false and rejected, showing the difference to be statistically significant. In simple words, the weight of the IUGR placentas was found lesser than normal placentas. (Table 2)

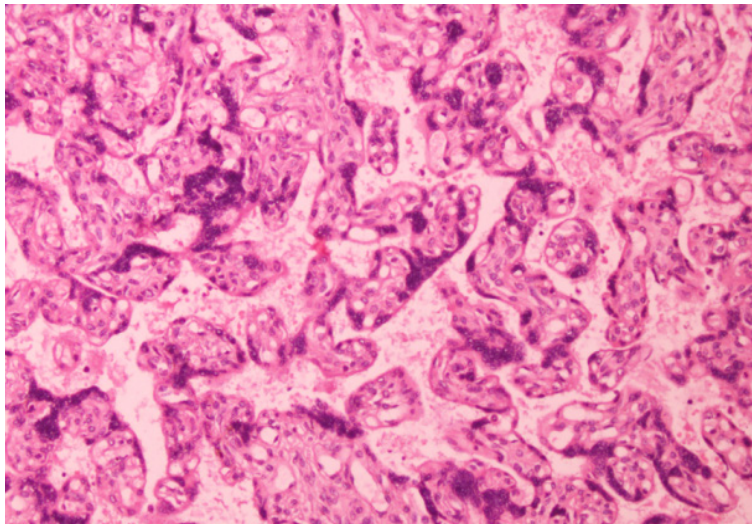

Figure 1: Photomicrograph of placental tissue from IUGR placentas displaying increased syncytial knotting in pregnant women of district Rawalpindi, Pakistan (H\&E stain x 400).

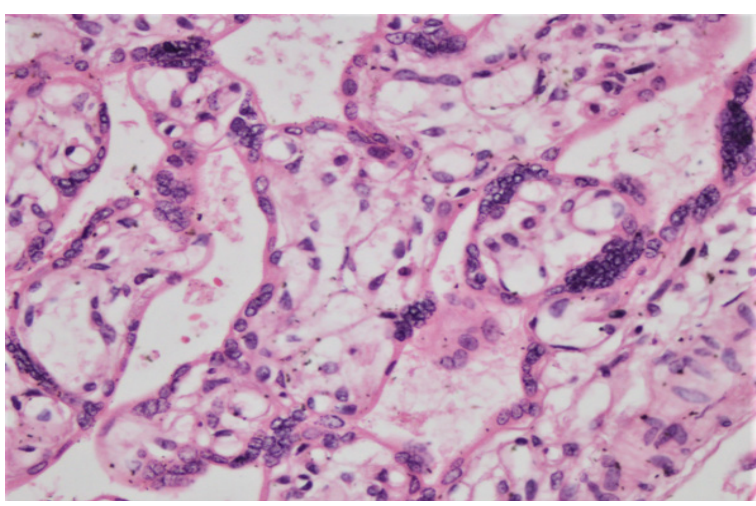

Figure 2: Photomicrograph of placental tissue from IUGR placentas revealing avascular villi in pregnant women of district Rawalpindi, Pakistan (H\&E stain $\times 40)$

Table 1: Descriptive Statistics \& Estimation of Parameters of Placentas in IUGR $(n 1=45)$ and control Groups $(\mathrm{n} 2=25)$ in pregnant women of district Rawalpindi, Pakistan

\begin{tabular}{|l|c|c|c|c|c|c|c|c|}
\hline \multirow{2}{*}{ Variables } & \multirow{2}{*}{ Group } & \multicolumn{9}{|c|}{ Sample Statistics } & \multicolumn{3}{c|}{$95 \%$ Cl of Mean } \\
\cline { 3 - 9 } & & Mean & Min. & Max. & Range & SD & Lower & Upper \\
\hline $\begin{array}{l}\text { Placental weight } \\
\text { (grams) }\end{array}$ & IUGR & 423.35 & 220 & 550 & 30 & 64.13 & 404.61 & 442.09 \\
\cline { 2 - 9 } & Control & 535.92 & 458 & 640 & 82 & 44.57 & 518.45 & 553.39 \\
\hline $\begin{array}{l}\text { Number of } \\
\text { syncytial knots }\end{array}$ & IUGR & 22.04 & 11 & 31 & 20 & 05.21 & 20.52 & 23.56 \\
\cline { 2 - 9 } & Control & 13.84 & 07 & 20 & 13 & 04.41 & 12.11 & 15.57 \\
\hline $\begin{array}{l}\text { Number of } \\
\text { blood vessels }\end{array}$ & IUGR & 01.71 & 01 & 03 & 02 & 01.03 & 01.41 & 02.01 \\
\cline { 2 - 9 } & Control & 03.60 & 02 & 06 & 04 & 01.11 & 03.12 & 04.03 \\
\hline
\end{tabular}

Table 2: Comparison of mean weight of placentas in IUGR group versus control group in pregnant women of district Rawalpindi, Pakistan

\begin{tabular}{|c|c|c|c|c|c|c|c|c|c|}
\hline \multirow{2}{*}{ Groups } & \multirow{2}{*}{$\mathrm{n}$} & \multirow{2}{*}{ Mean } & \multirow{2}{*}{ SD } & \multirow{2}{*}{$\begin{array}{l}\text { Mean differ- } \\
\text { ence }\end{array}$} & \multicolumn{2}{|c|}{$95 \% \mathrm{Cl}$ of difference } & \multirow{2}{*}{ t-value } & \multirow{2}{*}{ d.f. } & \multirow{2}{*}{$\begin{array}{l}\text { P-value } \\
\text { (2-tailed) }\end{array}$} \\
\hline & & & & & Lower & Upper & & & \\
\hline IUGR & 45 & 423.36 & 64.13 & -112.56 & -131.30 & -93.83 & -7.78 & 68 & $<.00001$ \\
\hline Control & 25 & 535.92 & 44.57 & \multicolumn{3}{|c|}{ Independent-Samples t-test } & \multicolumn{3}{|c|}{$\mathrm{H}_{0} 1$ rejected at $\alpha .05$} \\
\hline
\end{tabular}

$\mathrm{n}=$ Sample size, $\mathrm{SD}=$ Standard deviation, d.f. $=$ Degree of freedom 
Table 3: Comparison of mean number of syncytial knots in placentas in IUGR group versus control group in pregnant women of district Rawalpindi, Pakistan

\begin{tabular}{|c|c|c|c|c|c|c|c|c|c|}
\hline \multirow{2}{*}{ Groups } & \multirow{2}{*}{$\mathrm{n}$} & \multirow{2}{*}{ Mean } & \multirow{2}{*}{ SD } & \multirow{2}{*}{ Mean difference } & \multicolumn{2}{|c|}{$95 \% \mathrm{Cl}$ of difference } & \multirow{2}{*}{ t-value } & \multirow{2}{*}{ d.f. } & \multirow{2}{*}{$\begin{array}{l}\text { P-value } \\
\text { (2-tailed) }\end{array}$} \\
\hline & & & & & Lower & Upper & & & \\
\hline IUGR & 45 & 22.20 & 5.15 & 8.64 & 7.14 & 10.14 & 7.57 & 68 & $<.00001$ \\
\hline Control & 25 & 13.56 & 3.80 & \multicolumn{3}{|c|}{ Independent-Samples t-test } & \multicolumn{3}{|c|}{$\mathrm{H}_{0} 2$ rejected at $\alpha .05$} \\
\hline
\end{tabular}

$\mathrm{n}=$ Sample size, $\mathrm{SD}=$ Standard deviation, d.f. = Degree of freedom

Table 4: Comparison of mean number of vessels per terminal villus in placentas in IUGR group versus control group in pregnant women of district Rawalpindi, Pakistan

\begin{tabular}{|c|c|c|c|c|c|c|c|c|c|}
\hline \multirow{2}{*}{ Groups } & \multirow{2}{*}{$\mathrm{n}$} & \multirow{2}{*}{ Mean } & \multirow{2}{*}{ SD } & \multirow{2}{*}{ Mean difference } & \multicolumn{2}{|c|}{$95 \% \mathrm{Cl}$ of difference } & \multirow{2}{*}{ t-value } & \multirow{2}{*}{ d.f. } & \multirow{2}{*}{$\begin{array}{l}\text { P-value } \\
\text { (2-tailed) }\end{array}$} \\
\hline & & & & & Lower & Upper & & & \\
\hline IUGR & 45 & 1.75 & 1.01 & -1.97 & -2.27 & -1.67 & -7.03 & 68 & $<.00001$ \\
\hline Control & 25 & 3.72 & 1.31 & \multicolumn{3}{|c|}{ Independent-Samples t-test } & \multicolumn{3}{|c|}{$\mathrm{H}_{0} 3$ rejected at $\alpha .05$} \\
\hline
\end{tabular}

$\mathrm{n}=$ Sample size, $\mathrm{SD}=$ Standard deviation, d.f. $=$ Degree of freedom

$\mathbf{H}_{0}$ 2: Here the mean number of syncytial knots in IUGR placentas was compared to mean number of syncytial knots in Control group placentas through independent-samples t-test at alpha .05. As p-value was less than 0.05 , hence $\mathrm{H}_{0} 2$ was proved to be false and rejected, showing the difference to be statistically significant. In simple words, the number of syncytial knots in IUGR placentas was found higher than normal placentas. (Table 3)

$\mathbf{H}_{0}$ 3: Here the mean number of vessels per terminal villus in IUGR placentas was compared to mean number of vessels per terminal villus in control group placentas through independent-samples t-test at alpha .05. As p-value was less than 0.05 , hence $\mathrm{H}_{0} 3$ was proved to be false and rejected, showing the difference to be statistically significant. In simple words, the number of vessels per terminal villus in IUGR placentas was found lower than normal placentas. (Table 4)

\section{DISCUSSION}

Placentas of IUGR neonates show wide variety of lesions. It is not the focal villous lesion but the accumulation of placental injury that leads to IUGR.

4.1 Weight of placentas in IUGR group versus control group $\left(\mathbf{H}_{0} \mathbf{1}\right)$ : On gross examination, placental weight is significantly reduced in IUGR placentas when compared to normal. This is in accordance with the study of Ghomian et al. ${ }^{13}$ for the years 2007 and 2009 from Mashhad, Iran. Khajuria ${ }^{14}$ found placental weights to be 550 grams in the control group and 425 grams in the IUGR group with the differences being statistically significant for the year 2019 from Jammu and Kashmir, India. Similar study has been reported by Vedmedovska et al. ${ }^{15}$ for the years 2007 and 2008 from Riga, Latvia.

4.2 Number of syncytial knots in placentas in IUGR group versus control group $\left(\mathrm{H}_{0} 2\right)$ : Increased syncytial knotting is considered as a diagnostic indicator of decreased perfusion of the villi. Cytotro- phoblasts become prominent in order to replace damaged syncytiotrophoblasts. ${ }^{16}$ In current study the numbers of syncytial knots are found to be increased in IUGR placentas. Mardi and Sharma ${ }^{17}$ from Shimla, India, studied histological features of placenta in IUGR pregnancies in 2003 and showed an increase in the number of syncytial knots. Biswas et al. ${ }^{18}$ in 2012 from Kolkata, India, found high villous syncytial count in placentas of IUGR pregnancies. These findings are in agreement with our study.

4.3 Number of vessels per terminal villus in placentas in IUGR group versus control group $\left(\mathrm{H}_{0} 3\right)$ :

Hypovascularity of villi is found in of IUGR placentas which correlated with study of Hemalatha $M^{7}$ from Andhra Pradesh, India. Reduced number of vessels indicate disturbance in placental maturation due to decreased uteroplacental blood flow. ${ }^{19}$ Park et al. ${ }^{9}$ from Seoul, Korea, also observed groups of avascular villi indicative of fetal thrombotic arteriopathy in the IUGR cases.

All the major morphologic changes in IUGR placentas pointed toward decreased blood supply to placenta leading to chronic placental insufficiency and subsequently growth restricted fetus. The consequence of altered fetal growth is not restricted to the perinatal period but adult diseases are also caused by defective intrauterine growth. That's why a better understanding of the underlying placental pathological mechanism is required..$^{20}$

\section{CONCLUSION}

In this study, significant differences were found between the IUGR and normal group regarding the macroscopic and microscopic pathologic changes in placentas. All the major histologic findings pointed towards reduced blood flow to the placentas resulting in the restriction of blood flow to fetus. The information obtained from their examination can be a useful adjunct in planning and management of future pregnancies. 


\section{REFERENCES}

1. Salafia CM, Charles AK, Maas EM. Placenta and fetal growth restriction. Clin Obstet Gynecol 2006 Jun; 49(2):236-56. https://doi.org/10.1097/00003081200606000-00007

2. Jaddoe VW, De Jonge LL. Hofman A. Franco $\mathrm{OH}$. Steegers EA. Gaillard R. First trimester fetal growth restriction and cardiovascular risk factors in school age children: population based cohort study. BMJ 2014; 348:g14. https://doi.org/10.1136/bmj.g14

3. Burton GJ, Fowden AL, Thornburg KL. Placental origins of chronic disease. Physiol Rev 2016 Oct; 96(4):1509-65. https://doi.org/10.1152/physrev.00029.2015

4. Burkhardt T, Schäffer L, Schneider C, Zimmermann $\mathrm{R}$, Kurmanavicius J. Reference values for the weight of freshly delivered term placentas and for placental weight-birth weight ratios. Eur J Obstet Gynecol Reprod Biol 2006 Sep-Oct; 128(1-2): 248-52. https://doi. org/10.1016/j.ejogrb.2005.10.032

5. Sharma D, Shastri S, Sharma P. Intrauterine growth restriction: antenatal and postnatal aspects. Clin Med Insights Pediatr 2016; 10:67-83. https://doi. org/10.4137/CMPed.S40070

6. Suhag A, Berghella V. Intrauterine Growth Restriction (IUGR): Etiology and Diagnosis. Curr Obstet Gynecol Rep 2013; 2(2):102-11. https://doi.org/10.1007/ s13669-013-0041-z

7. Hemalatha M, Phani Kumar M, Jankai M, Dudala SR. Histopathological evaluation of placentas in IUGR pregnancies. Asian Pac J Health Sci 2014; 1(4):566-9. Available at: https://pdfs.semanticscholar.org/b095/ bce0c9e9108f82372eac5c5d7e8d0380dc53.pdf

8. Burton GJ, Jauniaux E. Pathophysiology of placental-derived fetal growth restriction. Am J Obstet Gynecol 2018; 218(2S):S745-S761. https://doi. org/10.1016/j.ajog.2017.11.577

9. Park SY, Kim MY, Kim YJ, Chun YK, Kim HS, Hong SR. Placental pathology in intrauterine growth retardation. Korean J Pathol 2002; 36:30-7. Available at: https:// www.jpatholtm.org/journal/view.php?number $=2142$

10. Bernard R. Fundamentals of Biostatistics. 8th ed. Boston, MA, USA: Cengage Learning; 2015.

11. Dean AG, Sullivan KM, Soe MM. OpenEpi: Open Source Epidemiologic Statistics for Public Health, Version 3.01. Sample size for comparing two means [up- dated 2013 Apr 6, accessed 2019 Jan 17]. Available at: https://www.openepi.com/SampleSize/SSMean.htm

12. Social Science Statistics. T-test calculator for 2 independent means. [Internet]. [cited 2019 Jan 17]. Available from: http://www.socscistatistics.com/tests/

13. Ghomian N, Amouian S, Tavassoli F, Arbabzadeh T. Comparison of placental morphology and histopathology of intrauterine growth restriction and normal infants. Iran J Pathol 2014; 9(1):9-16. Available at: https://pdfs.semanticscholar.org/f9ca/9cdb2a161afd7af6f4baa7de93e808c9536b.pdf

14. Khajuria R, Sharma M. Histopathology of placenta in intrauterine growth restriction (IUGR). Int J Res Med Sci 2019; 7(3):889-92. https://doi.org/10.18203/23206012.ijrms20190943

15. Vedmedovska N, Rezeberga D, Teibe U, Melderis I, Donders GG. Placental pathology in fetal growth restriction. Eur J Obstet Gynecol Reprod Biol 2011; 155(1):36-40. https://doi.org/10.1016/j. ejogrb.2010.11.017

16. Adil SAK, Nausheen R. Histopathological study of placenta in severe anemia during pregnancy. J Evo Med Dent Sci 2012; 4:616-23. https://doi.org/10.14260/ jemds/97

17. Mardi K, Sharma J. Histopathological evaluation of placentas in IUGR pregnancies. Indian J Pathol Microbiol 2003 Oct; 46(4):551-4. PMID: 15025340.

18. Biwa's S, Adhikari A, Chattopadhyay JC, Ghosh SK. Histological changes of placentas associated with intra-uterine growth restriction of fetuses: a case control study. Nepal Med Coll J 2012 Mar; 14(1):18-24. PMID: 23441489.

19. Mardi K, Negi L. Histopathological study of placentae in intrauterine growth retardation pregnancies in a tertiary care hospital and correlation with fetal birth weight. J Pathol Nepal 2017; 7(2):1176-9. https://doi. org/10.3126/jpn.v7i2.18003

20. Jansson T, Powell TL. Human placental transport in altered fetal growth: does the placenta function as a nutrient sensor? a review. Placenta 2006; 27(S): 91-7. https://doi.org/10.1016/j.placenta.2005.11.010

\section{CONFLICT OF INTEREST}

Authors declare no conflict of interest. GRANT SUPPORT AND FINANCIAL DISCLOSURE None declared.

\section{AUTHORS' CONTRIBUTION}

The following authors have made substantial contributions to the manuscript as under:

Conception or Design: $\quad$ NK, NA

Acquisition, Analysis or Interpretation of Data: $\quad$ NK, NA, TT, KS, TZ

Manuscript Writing \& Approval: $\quad$ NK, NA, TT, KS, TZ

All the authors agree to be accountable for all aspects of the work in ensuring that questions related to the accuracy or integrity of any part of the work are appropriately investigated and resolved. 